\title{
À sombra de Íris, as sombras de Eros: o espantar-se harpíaco na origem do olhar filosófico em Platão
}

\author{
IRLIM CORRÊA LIMA JUNIOR *
}

\begin{abstract}
RESUMo No passo $155 \mathrm{c}$-d do diálogo Teeteto, Platão faz uso da expressão tò thaumádzein para especificar o páthos (paixão, emoção, afecção...) próprio do despertar do pensamento filosófico. A expressão assinalaria algo como um admirar-se, um espantar-se ou assombrar-se, não como uma simples emoção que sucede à alma, mas, talvez, como um acontecimento inquietante, misto de admiração e de espanto, contendo um alto grau de imprevisibilidade. Platão, ao recordar a genealogia do deus Thauma, que representa o espanto, parece sugerir uma analogia entre o olhar filosófico e Íris, a deusa que personifica o arco-íris enquanto mediação entre os céus e a terra, o divino e o mortal. Sob a ótica platônica, e recordando que na iconografia a deusa, cujo nome também serve para designar a membrana ocular, possui um véu, Íris se identificaria com o olhar filosófico através do qual a verdade eterna do inteligível se revelaria para além do sensível. Nosso objetivo será o de, partindo de uma hermenêutica dessa passagem de Platão, prosseguir por especulação, chegando a aventar a ideia de que há sub-repticiamente uma filiação que não se encontra textualmente à vista, mas que, mesmo permanecendo à sombra, sem ser nomeada, seria possível e talvez necessária de se pensar: pois Thauma é pai também das Harpias, as quais são, portanto, irmãs de Íris. Deusas do arrebatamento súbito e mortal - a que devemos ligar o exáiphnes platônico, a subitaneidade do insight filosófico -, as Harpias, cujo nome tem correlação com o vocábulo harpýs (união íntima, relação amorosa), precisariam ser pensadas em conjunção com Íris e como uma imagem complementar ao Eros platônico do Banquete. Haveria, portanto, um elemento harpíaco intrínseco à gênese do pensamento filosófico: o acontecer fugaz de um arrebatamento.
\end{abstract}

PALAVRAS-ChaVe Platão; Teeteto; Banquete; Harpíaco; Espanto.

* Doutorando em Filosofia pela PUC-Rio Bolsista CAPES 
Dedico a Felipe Gall. Sem nossos diálogos, esse texto não aconteceria.

A Busca pela origem da filosofia começou, num único golpe, como uma reconstrução arqueológica e desconstrução do contemporâneo. Desde Platão e Aristóteles a tradição imputa a origem do filosofar ao $\theta \alpha \tilde{v} \mu \alpha$, palavra que pode apresentar os significados múltiplos, se bem que correlacionados, de espanto, assombro, surpresa, maravilhamento, admiração. Significados que são matizes de uma mesma experiência de tonalidade peculiar produzida sob a sensação abrupta de um deslocamento - e nessa medida, então, também de um descolamento.

Deslocamento e descolamento de um elemento-chave no contemporâneo, movimento que visa, num refluxo, a desconstrução de um jogo de forças predominante na atualidade, o que somente se logra por meio de um gesto conceitual de compreender por retroação o princípio fundacional do itinerário histórico da especulação filosófica, a fim de se apropriar de seu ato fundador. A contemporaneidade com que contende o filósofo, principalmente em Platão, extensível também para Aristóteles, deve ser vencida por meio da trans-histórica potência do pensamento especulativo, que recai sobre o atual de forma extemporânea, deslocando o discurso e a razão, o lógos, para fora do tempo presente, sincronizando o pensamento a temporalidades alternativas, nas quais a verdade, desprendendo-se das trânsfugas sombras hodiernas, se revelaria.

Ao intentar subjugar a contemporâneo, é mister espoliá-lo de suas armas. Daí a necessidade de Platão de estraçalhar em seus diálogos os discursos e argumentos de seus arqui-inimigos, os sofistas. Com efeito, que figura encarnaria melhor a decadência do tempo presente, que necessita urgente de correção, senão o sofista, caracterizado pelas suas habilidades ludibriosas de prestidigitação, a quem fora confiado a educação e

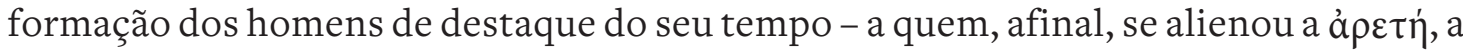
excelência/virtude? Não ao acaso, Sócrates recorrentemente simula o sofista - simulando, emula e, emulando, desmascara-os. Na alegoria da caverna, famosa passagem do Livro VII da República de Platão, na qual confluem o conteúdo epistemológico da linha dividida e as discussões de cunho pedagógico-político, os homens que gozam de liberdade na caverna, são aqueles que lançam mão de artefatos cujas sombras causam 
ilusão de realidade nos prisioneiros, parecidos com cada um de nós. Ludibriando os

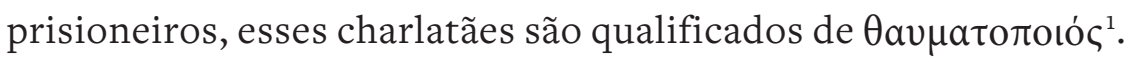

Esses ilusionistas, levantando um muro entre eles e o público, “demonstram suas

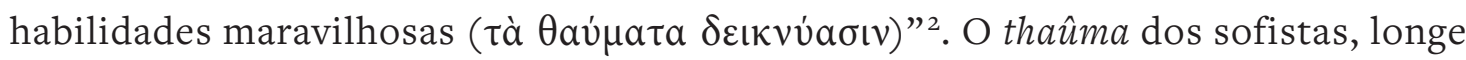
de se poder comparar à experiência da admiração, delineia-se aqui como um sortilégio, um estratagema operado por suas habilidades mágicas. Com efeito, Platão neste passo é fiel às metáforas elaboradas pela tradição sofística para caracterizar o poder encantatório do discurso de modular a crença e a opinião da alma, o que Górgias, no seu Elogio à Helena, como recurso de metalinguagem, compara ao encantamento das

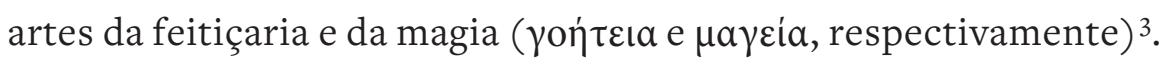

Define-se essa habilidade como maravilhosa não por se gerar de uma experiência de vida com aquilo que impacta imediatamente um assombro, mas sim por consistir na técnica de produção de mudanças de estados de ânimos na plateia por meio do expediente de truques ilusórios de fascinação, que a enfeitiça e a deixa mesmerizada dian-

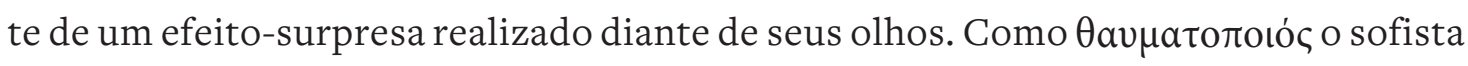
é um produtor da sensação de um susto do inesperado graças a suas técnicas, proporcionando ao espectador um encanto do qual o sofista ele mesmo jamais é afetado, por conhecer seus segredos. A prepotência por exercer tal poder, antes, imuniza-o diante da possibilidade real de sofrer qualquer fascínio, uma vez que, estando na perspectiva dos bastidores da prestidigitação, tudo resulta ser artifício de simulações.

Lançando os holofotes para o sofista, o efeito dos diálogos platônicos é o de lançar luz sobre a natureza artificial dessa técnica, revelando seus segredos, reduzindo-a a puro jogo de simulacros. De quebra, nesse gesto se revela o desencanto de que sofre seu mundo contemporâneo, sujeito às artimanhas e aos interesses dessa fábrica de estéreis fascínios.

Se o filósofo é aquele que se desprende dos grilhões, transcende as barreiras sofísticas e então ascende ao domínio da verdade, por conseguinte é ele quem possuirá por

1 PLATÃO, República, 514a, p. 573.

2 Modificamos ligeiramente a tradução presente na edição bilíngue: PLATÃO, República, 514b, p. 572573 .

3 GORGIAS, Encomium of Helen, p. 24-25. 
exclusividade a legítima afecção de admiração. Não como artifício, mas como experiência transgressora de fronteiras, através do que a contemplação da luz da verdade concretamente se revela ao pensamento filosófico. Mirando nisso é que devemos meditar no célebre excerto do Theeteto, que conteria o parecer de Platão acerca do surgimento da filosofia:

Theeteto: Pelos deuses, Sócrates, sinto um espanto $(\theta a v \mu a \dot{\zeta}(\omega)$ sobrenatural

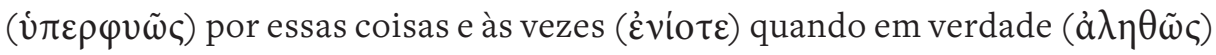
as observo $(\beta \lambda \dot{\varepsilon} \pi \omega v)$, desfaleço de vertigem ( $\sigma \kappa o \tau o \delta \iota \nu \tilde{\omega})$.

Sócrates: Meu caro, parece que Theodoro não julgou mal a tua natureza ( $\varphi v ́ \sigma ı)$,

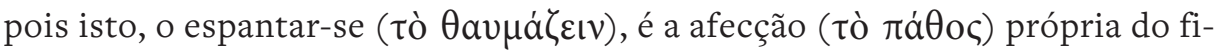

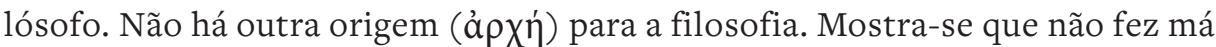
genealogia o que alegou ser Íris filha de Thaumas. ${ }^{4}$

Elegantemente conciso e alusivo, mas riquíssimo na urdidura textual, é que Platão monta os pontos nodais do seu próprio conceito de filosofia à guisa de um caleidoscópio, com seus rodopios visuais. A experiência de assombro do jovem Theeteto, nada obstante prematura, de modo algum é ilegítima. Não resta sombra de ironia no diagnóstico de Sócrates acerca da natureza desse sentimento que acomete seu interlocutor. Antes, reconhece precisamente nessa sensação o princípio e a origem da filosofia, sua ả $\chi \eta ்$. Nesse discurso arqueológico não se sugere a ideia de que a atividade filosófica consista num conhecimento dogmático; ao contrário, ela figura como pura irrupção de um estado de ânimo singular, que altera a percepção de realidade daquele que padece. Irrupção, aliás, que não é estanque e que não estabiliza nada, por não ser

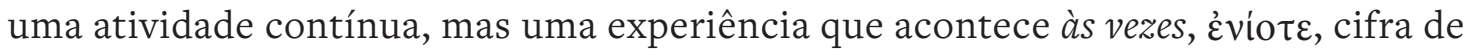
uma temporalidade intermitente e reiterável, acontecendo no instante fugaz de um brilho eterno, para onde, porém, se é possível a custo retornar.

Necessitamos frisar, antes de mais nada, a natureza dessa sensação. Platão poderia muito bem empregar aqui o vocábulo corrente $\theta a \tilde{\mu} \mu \alpha$, cuja gama de sentidos já explicitamos. Ao invés, apela para a forma substantivada do infinitivo presente ativo,

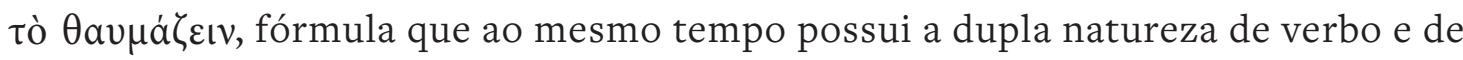

4 Tradução nossa com base na edição do texto original: PLATO. Theaetetus. In: Platonis Opera, ed. John Burnet. Oxford University Press. 1903, 155c-d. Disponível em: http://www.perseus.tufts. edu/hopper/text?doc $=$ Plat. + Theaet.+155\&fromdoc=Perseus\%3Atext\%3A1999.01.0171 
substantivo. Nesse sentido, tò thaumádzein assinalaria algo como um admirar-se, um espantar-se ou assombrar-se, não como uma simples emoção que sucede à alma, mas, talvez, como uma intercorrência que a arrebata, um acontecimento inquietante misto de admiração e de espanto e que seria, de algum modo, imprevisível. O uso do infinitivo marcaria essa diferença - que é a diferença crucial e decisiva da experiência filosófica contra as demais experiências de vida - entre emoção e experiência. Ademais, serviria ainda para explicitar a ação ou paixão que se imprime na alma de Theeteto, uma vez que ele confesse, diante dos rodopios dialéticos com Sócrates, estar espantado - sinto um espanto $(\theta a v \mu a ́ \zeta(\omega)$, ele mesmo diz, como quem está aturdido.

Traduzimos literalmente o advérbio que qualifica essa ação-paixão, a fim de reproduzirmos uma possível nuance do texto platônico. A tradução mais gramatical talvez exigisse um advérbio de intensidade, mas ao preferirmos a expressão sobrenatural

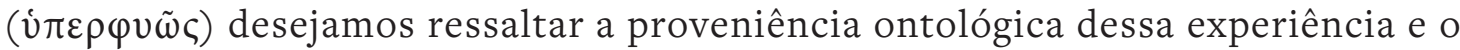
redirecionamento epistemológico que ela, numa reviravolta com o mundo da vida,

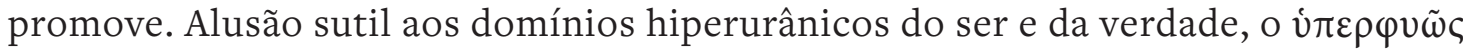
caracterizaria esse espanto como uma espécie de arrebatamento, deslocando a alma

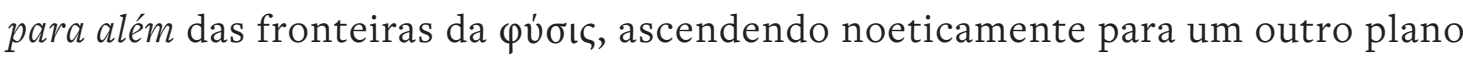
do ser, até então indiviso. Devemos decodificar nesse v̇ $\varepsilon \rho \varphi v \tilde{\omega} \varsigma$ do sobrenatural a senha do suprassensível, passe que lhe descerra o acesso. Nessa experiência rompe-se com as sombras e as aparências, assentadas no solo do sensível e da experiência empírica dela proveniente - a alusão ao sensível é construída pela equivalência en-

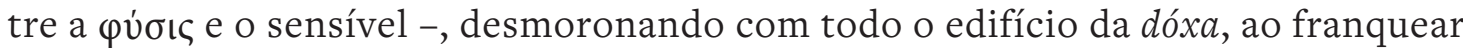
a intelecção da verdade - ainda que, nesses primeiros arrojos da razão, apenas siga o intelecto devagar e confuso, tateando às cegas no escuro, qual o prisioneiro que, ao libertar-se da caverna, precisa gradativamente acostumar-se à luz, sem avistá-la diretamente, porquanto retenha em seus olhos densa escuridão. Essa intelecção da verdade insinua-se quando Theeteto alega que o assombro advém no preciso instante em que em verdade observa: observação, evidente, que não é da ordem do sensível, mas do racional-passional. É o plano da inteligibilidade que começa a raiar diante do seu intelecto, e o impacto desta visualização abrupta e extática causa-lhe um desfalecimento de vertigem, expressa pelo verbo $\sigma \kappa o \tau o \delta ı v \tilde{\omega}$, que reúne a penumbra e o turbilhão, sensações de quem está perdendo os sentidos, erodindo-se o firme solo em que pisa, encontrando-se, portanto, à mercê das trevas que o envolvem como um 
redemoinho. A perda dos sentidos e o turbilhão são imagem da quebra com a orientação fática do sujeito com as crenças e a dóxa, ícone, portanto, da cisão com o mundo das aparências, o que ocorre por um sobrelevar da razão ao inteligível, em que a realidade aparece-lhe transfigurada. A verdade ainda não é nítida - aqui ela se confunde à experiência da perda dos sentidos, carecendo da consolidação dialética que regula o foco da razão à transcendência do que é imaterial e eterno.

Theeteto personifica aquele que está sendo introduzido na experiência filosófica. Nele estão ruindo as opiniões protagóricas e heraclíticas, imersas nas sombras, vislumbrando ao longe um facho de luz. Sócrates ratifica um juízo feito à excelente natureza,

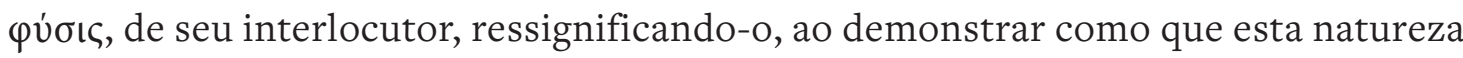
revela uma inerente inclinação ao páthos, afecção ou emoção, que distingue o filósofo.

O arremate socrático é o de que acertou quem conectou, por genealogia, a ascendência da deusa Íris a partir de Thaumas, deus que simboliza o espanto e a sensação de surpresa e que, segundo a Teogonia de Hesíodo, era filho de Pontos, o mar, e Gaia, terra 5 - e, nesse sentido, o assombro se assemelharia às ondas, movimento de eterno retorno, indo e voltando em insaciável busca da terra firme, matriz e nutriz originária da realidade e da vida. Na Ilíada, Íris, que na iconografia é desenhada possuindo asas e coberta por um véu, é retratada como a divindade que, representando o arco-íris como força e fenômeno singulares da natureza, estabelecendo uma ponte que unifica céus e terra, faria a mediação entre a realidade divina e a mortal, cumprindo, numa versão feminina, a mesma função de Hermes, como mensageira entre deuses e homens.

A referência a essas divindades não é ao acaso; ao contrário, adiciona um espectro de cores que tornam o texto platônico um tecido ainda mais plural em suas nuances e significados. Se Thaumas equivale ao tò $\theta a v \mu a ́$ Čı como arkhé da filosofia, então Íris personifica olhar filosófico, o que é ainda mais indicativo disto é que a palavra grega ı́ ıı, assim como nas línguas neolatinas, signifique outrossim a membrana interna do olho. Thaumas é, portanto, a origem da experiência da visão filosófica - esta última, como descendente de uma afecção arrebatadora, mostrar-se-ia a mediação que transporta a inteligência humana às extremidades do ser e da verdade. A mensagem que ela carrega são os desdobramentos conceituais que se erigem dialeticamente do

5 HESÍODO, Teogonia, vv. 233-239, p. 46-47. 
solo especulativo, até se elevarem à transcendência da intuição noética, logrando o aspecto definitivo das formas, quer dizer, das ideias enquanto conceitos que definem o plano da realidade dentro de um horizonte de hiperdefinição, perspectiva de alta resolução a partir da qual a verdade aparece filtrada das sombras das aparências e das opiniões, tornando-se nítida teia de múltiplas relações ontológicas que visam apreender a essência de cada ser.

Ponte que vai do sensível ao suprassensível, ela não seria, dentro da estrita definição de divindade conforme Platão elabora no Banquete, propriamente uma deusa, mas, tal qual Eros, um $\delta a i \mu \omega v$, força que atua entre as dimensões terrena e celeste, participando de dupla natureza que possibilita a intercomunicação e o vínculo entre ambas, duplo movimento de deslocamento entre uma e outra, ascensão e declínio, instante efêmero de intuição iluminadora e momento em que esta se desfaz, cerrando os olhos à sua visualização. O véu que porta consigo é ícone desta ambivalente relação de velamento e de desvelamento intrínseca à dinâmica da verdade sob a ótica da ả $\lambda \dot{\eta} \theta \varepsilon ı$, no sentido mesmo de um evento momentâneo de revelação.

Às ocultas no que é expresso no texto, há uma filiação tortuosa que nos é legítimo considerar como possibilidade que ampliaria o alcance das imagens empregadas por Platão, dado o leque imagético com que se revestem as figuras de Íris e de seu pai. A paternidade de Thaumas cobre também a das harpias, irmãs monstruosas da bela Íris, aberrações aladas que possuíam busto de idosas decrépitas e corpo de abutre. Originalmente em número de duas, Aelo, a borrasca ou a impetuosa, Ocipite, a rápida no voo, tornaram-se posteriormente, com o acréscimo de Celene (cujo nome significa a obscura), um trio, ávidas todas de sangue e de sexo. Na época clássica assombravam a imaginação dos gregos como monstros medonhos e horripilantes, podendo-se interpretá-las como "parcelas diabólicas das energias cósmicas, as abastecedoras do Hades com mortes súbitas.”6

Etimologicamente talvez relacionadas com o verbo grego á $\rho \pi \dot{\alpha} \zeta \varepsilon \iota v$ e com o latim rapere, arrebatar ou raptar, personificariam o próprio movimento abrupto de arrebatamento. Rapto pelo divino ou pelo que simplesmente transcende o plano da mortalidade - e precisamos associar aqui a condição mortal atrelada à vida corporal

6 BRANDÃO, Dicionário mítico-etimológico, p. 284. 
intimamente ligada ao que se conhece pelos sentidos, às potências do corpo sujeitas à transitoriedade das experiências, da vida de forma geral e do próprio tempo -, dada a iconografia dúbia que ora as retratam nos moldes das representações clássicas das fontes literárias como seres terríveis, ora como entidades de belo aspecto, próximos a figuras angelicais, carregando a alma de recém-nascidos, é perfeitamente capaz que tenham surgido no princípio como divindades ctônicas que "têm por objetivo a união íntima com aqueles que arrebatavam"7, mas que, com o decorrer dos séculos e a consolidação da religião olímpica que privilegia as figuras filiadas às potências solares e celestiais - de matriz patriarcal - em detrimento das potências ligadas à terra e à fertilidade - enquanto entidades matriarcais -, sofreram um processo gradativo de demonização até se tornarem definitivamente personagens sinistras.

Nesse malabarismo sofisticado de associações é que somos capazes de compreender então a conexão que haveria entre o nome das harpias, 'A $\rho \pi v ı$ เ, e o vocábulo ä $\rho \pi v \varsigma$, união íntima, relação de amor. Essa possível relação entretece-se a partir da aproxi-

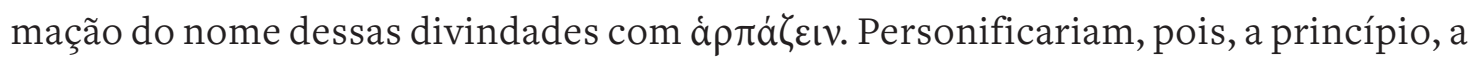
união íntima de amor que subitamente arrebata a alma do mortal, transportando-o à experiência de um êxtase inebriante, como se fosse uma experiência de orgasmo tão intenso a ponto de se ser análoga à experiência da morte, singrando da intensidade máxima ao desfalecimento dos sentidos. Aelo, Ocipite e Celene - nomes de uma trindade que personificam uma experiência una e singular - representariam respectivamente: o instante impetuoso de êxtase que recai como uma borrasca, outra imagem para o turbilhão que confessou sentir Theeteto; a fugacidade lesta desse instante extático; e, por fim, o delíquio subsequente, com a perda dos sentidos e o obscurecimento similar ao desmaio ou à morte.

Independente se forçamos demasiado a interpretação, o que há de mais valioso é enxergar sob um novo enfoque as ricas nuances que sobrepairam ao texto platônico, e que nos convidariam a multiplicar seus sentidos, traçar novas conexões, amplificando o manancial de sua escrita com a afluência de outras possibilidades de leituras e conjeturas.

Se o que aventamos é válido ou ao menos plausível, então não deveríamos lobrigar em todo esse mundo de referências que permeiam as imagens do texto platônico aquela

7 Idem, ibidem, p. 284. 
mesma experiência erótica que caracteriza a contemplação filosófica no Banquete? O processo gradual de ascensão do conhecimento do belo, que começa com a força de atração voluptuosa pela beleza sensível presente nos corpos, até atingir a culminância da satisfação plena do desejo com o êxtase intelectual da visão do belo; enfim, em tudo isso precisamos abrir os olhos para ver como que esse escalonamento é insuficiente para apreender essa experiência, muito embora ele lhe seja exigido como conluio de forças que a preparam.

Aquele, pois, que até esse ponto tiver sido orientado para as coisas do amor

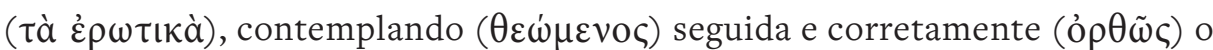

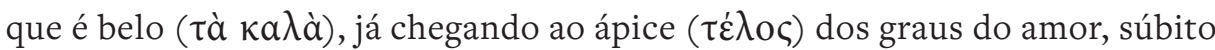

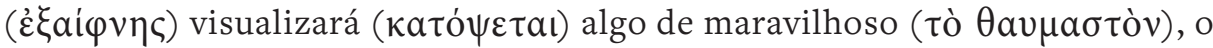

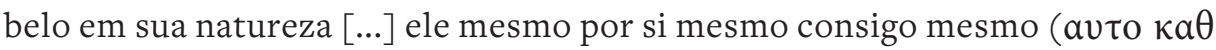

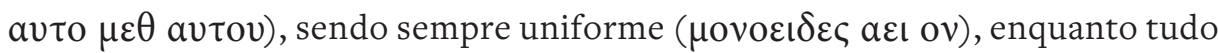

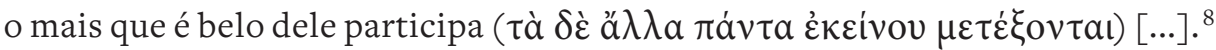

A contemplação ininterruptamente correta, mediante a intensificação do método dialético, galgando de grau em grau as escalas do que se mostra como partícipe do que é belo, proporcionaria um processo de ascensão em direção à verdade, mas a visualização daquilo que é o ser que permanece sempre o mesmo, uniforme, idêntico eternamente a si mesmo, só efetua-se mediante um corte abrupto, um salto a partir dos limites últimos da contemplação ascendente em direção à visualização transcendente, entre essas duas zonas. A verdade é um instante súbito de epifania, de revelação, de visualização surpreendente e desnorteante, em que as aparências se desfazem, caem as opiniões, os múltiplos discursos sobre o belo - símbolo da fulguração do próprio ser, da realidade originária e permanente em seu mais alto grau de pureza e excelência- para então irromper a intelecção do verdadeiro, imutável e inteligível. Retira-se o véu de Íris: à íris da razão então se desvela o mundo inteligível como fonte de onde a verdade e o ser emanam, experiência que é descrita como o maravilhoso,

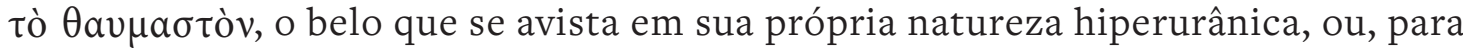

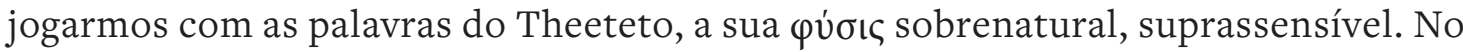
diálogo Theeteto, Íris e Thaumas representam essa copertença essencial entre intui-

8 PLATÃO. Banquete, 210e-211a, p. 48. Fizemos ligeiras alterações na tradução e colocamos entre parênteses os termos em grego com base na edição: PLATO. Symposium. In: ed. John Burnet. Oxford University Press. 1903, 210e-211a. Platonis Opera, 
ção filosófica - a visualização que depende de um preliminar condicionamento da contemplação através do método dialético - e o assombro com o maravilhoso, a verdade do que é por si mesmo e consigo mesmo, a realidade inteligível que unifica a multiplicidade dos fenômenos, o conceito pelo qual a essência do ser se apreende e se apresenta. Mas ambos, Íris e Thaumas, como fórmula matriz dessa experiência, requisitam um elemento inominado, algo que jamais se deixa traduzir nos escritos platônicos, como potência que resiste aos assaltos da escrita, jamais se permitindo escrever, descrever e se prescrever, a experiência singularíssima, portanto, de um arrebatamento extático, o insight do pensamento, o instante inefável da intuição filosófica. Por ser inefável, dela não se podendo falar ou escrever, é que as harpias ficam à margem, às ocultas como forças que atuam às margens do texto, mas não são nomeadas; exercem seu poder, mas não se mostram. Seu encantamento é exatamente o mesmo que realiza Eros como força pulsional que do sensório conduz ao inteligível.

Versão feminina de Eros, como Íris sói ser de Hermes, as harpias encarnam o instante abrupto do acontecimento filosófico, arkhé da filosofia. Nada de se imaginar aqui um castelo do saber sobre o qual se consolida a epistéme. Isso só é possível com Aristóteles, porque ele transforma o télos da filosofia em superação das dúvidas através do conhecimento, reduzindo a experiência do assombro ao estágio de ignorância a ser ultrapassado pelo entendimento das causas e dos princípios atuantes. O assombro em Aristóteles é uma mera patologia da ignorância; no fundo, não difere tanto da estrutura do assombro dos sofistas (a que se acrescenta o ingrediente da curiosidade natural do desejo pelo conhecimento). A maior diferença é que nos sofistas cria-se um teatro para produzi-lo, ao passo que na Metafísica se evidencia como que a natureza é ela mesma esse teatro de fantoches cujos mecanismos a princípio desconhecemos, mas, tão logo sabemos, desvanecem-se as dúvidas e com elas todo o encanto 9 .

Em Platão, pelo contrário, o télos, como lemos na passagem do Banquete, é o ápice do instante súbito da intuição. Platão não esconjura as harpias como ousou fazer o espírito apolíneo e metafísico que move as investigações aristotélicas, sempre à prontidão para debelar a força demoníaca das harpias que vem lhe assombrar com suas aporias. Esta trindade inefável é atuante no texto platônico, pairando ao redor de suas imagens e metáforas, destiladas nas lacunas de suas entrelinhas. Sua atuação

9 ARISTÓTELES, Metafísica, A-II, 982b 11-16, p. 10-11. 
faz-nos perder os sentidos, lançando-nos num turbilhão impetuoso em que sentimos a perda súbita de nossos sentidos, obscurecendo-nos o plano sensível em que nos apoiamos correntemente. Elas nos raptam do sensível para nos apresentarem num jato o suprassensível, união íntima e erótica entre amante e amado, filósofo e a verdade, o intelecto e a essência, o lógos e o real.

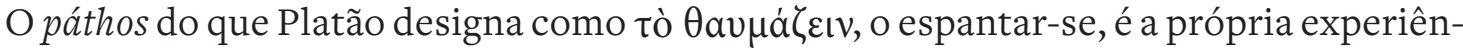
cia viva, intensa e momentânea do que é espantoso, tò $\theta \alpha u \mu \alpha \sigma \tau o ̀ v$, fonte e origem da verdade e da filosofia. Os diálogos de Platão, todos eles, perseguem essa experiência, obsediam-na sofregamente, uma vez que ela seja sempre fugaz, fugidia. Sem jamais se consolidar - sem jamais consolidar fundamentações -, essa experiência exaiphnética - abrupta, súbita - é um arrebatamento extático que é origem e ápice, arkhé e télos, do pensamento filosófico. Momentânea, toda a dialética move-se como espiral desdobrando-se $e^{10}$ em direção ao instante do advento da verdade. Do que espanta advêm a intuição e o arrebatamento, instante único de tríplice configuração, êxtase que se mostraria congênere ao entusiasmo divino dos poetas, descrito pelo próprio Sócrates no Íon ${ }^{11}$, lançando-os para fora de si mesmos, raptando-os ao jugo das musas, que respondem pelo princípio sobrenatural da potência poética. O pensamento platônico tece-se artisticamente por compreender claramente que não há distinção absoluta entre poesia e filosofia - ambas potências eróticas. A inspiração cede lugar à intuição, o entusiasmo ao espanto, as musas às harpias... Nesse intenso jogo de drásticas mudanças, porém, sua filosofia há de permanecer essencialmente uma poética do pensamento, visando continuamente o acontecimento efêmero e a afecção única do instante de transcendência da razão a exceder as sombras da natureza na contemplação do ser e da verdade. Múltiplas devem ser as extasiantes visões sob as quais as essências num átimo se mostram, como poliformes aspectos maravilhosos do que é consigo mesmo uniforme, mas jamais idêntico e repetido para a vida das experiências filosóficas.

Designemos, pois, de harpíaco a personificação mitológica e imagética do exáiphnes que advém com o espanto - páthos do thaûma - e a momentânea e fugaz transfiguração do olhar que instaura o olhar suprassensível e filosófico que transcende o mundo sen-

10 Convém recordar que a palavra íris provém da raiz indo-euripeia *wi, dobrar. Cf. BRANDÃO, Dicionário mítico-etimológico, p. 359.

11 PLATÃO, Íon, 533d, p. 48-49. 
sível e seu horizonte. O harpíaco é a imagem da intuição abrupta que eleva o olhar noético - a íris do pensamento no instante da alétheia - à contemplação e à revelação do real (assim, o olho do noûs, da percepção racional a partir do qual o real se transfigura em uma tessitura, symploké, rede de entrelaçamentos, ordenamentos, encadeamentos, relações, hierarquias, planos, definições, diferenciações... enfim, tudo o que inteligibiliza o múltiplo dessa carnadura - aparentemente atômica, fragmentária e dispersa - da realidade). O harpíaco, portanto, é uma imagem que não aparece no texto platônico justo porque a materialidade do texto jamais poderá inscrever aquilo que as harpias incorporam: elas personificam um arrebatamento súbito e prenhe de violência, o êxtase da alma no irromper da intuição, o acontecimento impossível de ser traduzido em simulacros, impassível de se deixar apreender pela escrita, pois é o evento abrupto, o exáiphnes, da experiência filosófica que exclusivamente pode receber como suporte a materialidade viva, invisível e espontânea da alma. E se só a vida inscreve o harpíaco na alma, as harpias, portanto, poderão apenas pairar sobre o texto platônico. Eros pode figurar na escrita porque ele é a força sinergética impulsionadora da busca filosófica, da maiêutica, da hetero e da autopoiese da experiência de pensamento, inerente à escrita; mas à sombra de Eros, lá estarão as harpias como sombras imprescindíveis, sem as quais o texto não pode atingir sua plenitude - e, devemos sublinhar, consideramos o próprio texto platônico múltiplas encarnações de Eros, e portanto toda a literatura de Platão seria erótica. O Eros é a pulsão da escrita, a potência que produz o texto platônico. Eros identifica-se com o corpus do texto platônico, essa matéria múltipla grávida de pensamentos filosóficos. O acontecimento de dar à luz somente é possível mediante e no olhar que se debruça sobre o texto e que se deixa contagiar com o gérmen que eles contém do maravilhamento e o espanto. O harpíaco é a mídia imaterial da experiência de uma ignição filosófica propiciada mas jamais predita ou premeditada pelo texto. É um acontecimento extratextual, o súbito que faz transladar do texto à vivência única, singular, irrepetível, intraduzível da experiência filosófica. O harpíaco é a imagem-sugestão subliminar dessa experiência abrupta. E, além disso, a expressão de sua temporalidade intermitente - o exáiphnes, o evento da erupção e da produção mais essencial da alétheia, revelação instantânea e fugaz do próprio real. 
Post-scriptum: Desenvolvido pela escrita nesse gênero poético inovador a que designamos diálogo filosófico, o teatro platônico é genuinamente dramático, ao contrário do teatro de ventríloquos sofístico. Consistiria, pois, no drama do conceito em sua hýbris trágica para a ideação transcendente da verdade. Hýbris jamais obra exclusivamente humana, já que ela é originariamente intrínseca à ideia, ao plano do inteligível. Parafraseando Eurípides, é o imprevisível que, excedendo o previsto - o que se prevê e se antevê -, se torna visível e viável para além das aporias graças às forças demoníacas das harpias para além da potência do texto e da escrita. Abruptamente, essa intuição acontece e se esvai. Platão jamais abandonou a tragédia para seguir Sócrates. Antes da (anti)trágica morte de Sócrates, ele enxergou a tragédia das palavras no pensamento. Harpias e Eros, outras metamorfoses de Dioniso. A filosofia é a máscara de um evento trágico e inefável. Paradoxalmente, esse evento é o realizar-se da própria máscara.

\section{REFERÊNCIAS BIBLIOGRÁFICAS}

aRISTÓTELES, Metafísica. Vol. II - texto grego e tradução de Giovanni Reale. São Paulo: Ed; Loyola, 2002.

BRANDÃO, Junito de Souza. Dicionário mítico-etimológico. Petrópolis: Vozes, 2014. GORGIAS. Encomium of Helen. Trad. D. M. MacDowell. Bristol: Bristol Cassical Press, 1982. HESÍODO. Teogonia. Edição bilíngue. Trad. Christian Werner. São Paulo: Hedra, 2013. PLATÃO. A República. Edição bilíngue. Trad. Carlos Alberto Nunes. Belém: Ed. UFPA, 2016. Banquete. Trad. José Cavalcante de Souza. In: . Diálogos. Coleção: Os Pensadores. São Paulo: Victor Civita, 1972. Ín. Edição bilíngue. Trad. Victor Jabouille. Lisboa: Editorial Inquérito, 1988. PLATO. Symposium. In: . Platonis Opera, ed. John Burnet. Oxford University Press. 1903. Disponível em: http://www.perseus.tufts.edu/hopper/text?doc=Perseus\%3Atext\% 3A1999.01.0173\%3Atext\%3DSym. Acessado em: 15 de agosto de 2018.

Theaetetus. In: . Platonis Opera, ed. John Burnet. Oxford University Press. 1903. Disponível em: http://www.perseus.tufts.edu/hopper/text?doc=Perseus\%3Atext\% 3A1999.01.0171\%3Atext\%3DTheaet. Acessado em: 15 de agosto de 2018. 